\title{
INTERPLAY BETWEEN BRAIN-DERIVED NEUROTROPHIC FACTOR AND SIGNAL TRANSDUCTION MODULATORS IN THE REGULATION OF THE EFFECTS OF EXERCISE ON SYNAPTIC-PLASTICITY
}

\author{
S. VAYNMAN, ${ }^{a} Z$. YING ${ }^{a}$ AND F. GOMEZ-PINILLA ${ }^{a, b *}$ \\ ${ }^{a}$ Department of Physiological Science, UCLA, 621 Charles E. Young \\ Drive, Los Angeles, CA 90095, USA \\ ${ }^{b}$ Division of Neurosurgery, UCLA Brain Injury Research Center, Los \\ Angeles, CA 90095, USA
}

\begin{abstract}
This study was designed to identify molecular mechanisms by which exercise affects synaptic-plasticity in the hippocampus, a brain area whose function, learning and memory, depends on this capability. We have focused on the central role that brain-derived neurotrophic factor (BDNF) may play in mediating the effects of exercise on synapticplasticity. In fact, this impact of exercise is exemplified by our finding that BDNF regulates the mRNA levels of two end products important for neural function, i.e. cAMP-responseelement binding (CREB) protein and synapsin I. CREB and synapsin I have the ability to modify neuronal function by regulating gene-transcription and affecting synaptic transmission, respectively. Furthermore, we show that BDNF is capable of concurrently increasing the mRNA levels of both itself and its tyrosine kinaseB (TrkB) receptor, suggesting that exercise may employ a feedback loop to augment the effects of BDNF on synaptic-plasticity. The use of a novel microbead injection method in our blocking experiments and Taqman reverse transcription polymerase reaction (RT-PCR) for RNA quantification, have enabled us to evaluate the contribution of different pathways to the exercise-induced increases in the mRNA levels of BDNF, TrkB, CREB, and synapsin I. We found that although BDNF mediates exerciseinduced hippocampal plasticity, additional molecules, i.e. the $\mathrm{N}$-methyl-D-aspartate receptor, calcium/calmodulin protein kinase II and the mitogen-activated protein kinase cascade, modulate its effects. Since these molecules have a well-described association to BDNF action, our results illustrate a basic mechanism through which exercise may promote synaptic-plasticity in the adult brain. (๑ 2003 IBRO. Published by Elsevier Ltd. All rights reserved.
\end{abstract}

Key words: CREB, synapsin I, NMDA-R, CAMKII, MAP-K, learning.

\footnotetext{
${ }^{*}$ Correspondence to: F. Gomez-Pinilla, Department of Physiological Science, UCLA, 621 Charles E. Young Drive, Los Angeles, CA 90095, USA. Tel: +1-310-206-9396; fax: +1-310-206-9396.

E-mail address: fgomezpi@ucla.edu (F. Gomez-Pinilla).

Abbreviations: BDNF, brain-derived neurotrophic factor; CAMKII, calcium/calmodulin protein kinase II; CREB, cAMP response-elementbinding protein; $\mathrm{C}_{\mathrm{T}}$, threshold cycle; Cyt.C, cytochrome $\mathrm{C}$; GAPDH, glyceraldyehyde-3-phosphate dehydrogenase; LTP, long-term potentiation; MAP-K, mitogen-activated protein kinase; NMDA-R, $N$ methyl-D-aspartate receptor; RT-PCR, reverse transcription polymerase chain reaction; SV, synaptic vesicles; TrkB-R, tyrosine kinase receptor; UNG, uracil glycosylase.
}

Exercise has been shown to enhance memory and cognition (Fordyce and Wehner, 1993; Kramer et al., 1999), facilitate functional recovery following brain injury (Grealy et al., 1999), promote neurogenesis in the adult brain (van Praag et al., 1999b), and even ameliorate the mental decline associated with aging (Laurin et al., 2001). The mechanisms through which exercise benefits the brain are poorly understood but they likely involve changes in synaptic-plasticity, the property that enables a neuron to harness activity into structural and functional changes at the synapse.

Recently, brain-derived neurotrophic factor (BDNF), initially delimited to the survival, growth, and differentiation of neurons during development (Barde, 1994), has emerged as a critical modulator of synaptic-plasticity in the adult brain (Lo, 1995). Particularly in the hippocampus, the site that has long been held as the vitae of learning and memory, manipulations in BDNF modulate synaptic structure and function. For example, BDNF gene deletion or inhibition (Figurov et al., 1996; Kang et al., 1997) produces a deficit in long-term potentiation (LTP), the transcriptiondependent synaptic candidate underlying learning and memory (Nguyen and Kandel, 1996). This deficit in synaptic function can be amended by exogenous application (Patterson et al., 1996) or overexpression (Korte et al., 1995) of BDNF.

Our goal is to bring to light signal transduction pathways and the avenue occupied by BDNF through which exercise may affect hippocampal plasticity. We have focused these studies on measuring two possible consummate targets of synaptic-plasticity, which are also closely associated to the action of BDNF. They are calcium and cAMP response-element-binding (CREB) protein a transcription factor that mediates many of the actions of the CAMP cascade on gene expression (Meyer et al., 1993), and synapsin I, a vesicle associated phosphoprotein engaged in transmitter release (Baekelandt et al., 1994).

To determine the molecular delegates that exercise employs to regulate CREB and synapsin I mRNAs, we manipulated alternative signaling pathways from which they can ensue. In addition, since BDNF is subject to feedback loops that utilize synaptic activity to coordinate its expression and that of its cognate tyrosine kinase receptor (TrkB-R; Shieh and Ghosh, 1999; Tao et al., 1998), we measured BDNF and TrkB mRNAs under the same paradigm. Specifically, BDNF may employ the $N$-methyl-D-aspartate receptor (NMDA-R) to increase its own mRNA (Suen et al., 1997). It is thought that NMDA-R activation (Ghosh et al., 1994) can initiate calcium/calmodulin protein 
kinase II (CAMKII; Platenik et al., 2000) to converge on the mitogen-activated protein kinase (MAP-K) cascade (Bading and Greenberg, 1991). In turn, MAP-K is able to induce the expression of plasticity-dependent genes (Cammarota et al., 2000). In addition, BDNF may engage its TrkB-R (Barbacid, 1994) to activate MAP-K (Stephens et al., 1994; Curtis et al., 1999). MAP-K has been shown to mediate synaptic-plasticity by phosphorylating synapsin I (Jovanovic et al., 1996) and CREB (Finkbeiner et al., 1997). These observations have suggested to us that exercise may employ the NMDA-R, CAMKII, and MAP-K, in addition to BDNF, to perpetuate feedback loops that would enable the augmentation of BDNF, TrkB, CREB, and synapsin I mRNA levels in the hippocampus. Although recent findings have shown that MAPK and CREB are activated in the hippocampus during exercise (Shen et al., 2001; Molteni et al., 2002b) the underlying signaling pathways and their interaction with BDNF remain poorly understood. Therefore, we performed this study to examine the signaling mechanisms, involving the TrkB receptor, the NMDA receptor, MAPK, and CAMKII, and their effect on BDNF and exercise mediated synaptic plasticity.

\section{EXPERIMENTAL PROCEDURES}

\section{Exercise paradigm}

Adult male Sprague-Dawley (Charles River) rats (approximately 3 months of age) were randomly assigned to a control group or exercise group ( $n=5-8$ animals per group). All rats were individually housed in standard polyethylene cages in a 12-h light/dark cycle at $22-24{ }^{\circ} \mathrm{C}$, with food and water ad libitum. The exercise rats were given access to a wheel (diameter $=31.8 \mathrm{~cm}$, width $=10 \mathrm{~cm}$ ) that freely rotated against a resistance of $100 \mathrm{~g}$ attached to a receiver that monitored revolutions every hour (VitalViewer Data Acquisition System software, Minimitter Company, Inc., Sunriver, OR, USA). The control rats were confined to a cage with no access to a wheel. We chose a voluntary exercise paradigm because it simulates aspects of human behavior in which animals choose how much to run. The exercise rats were given three or seven nights of wheel running. All rats were killed and brain tissue was collected the morning after the last running period. For biochemical assays, the animals were killed by decapitation and their hippocampi were rapidly dissected out, immediately placed on dry ice, and stored at $-70{ }^{\circ} \mathrm{C}$. All experiments were approved by the UCLA Animal Research Committee and were performed in accordance with the National Institute of Health Guide for the Care and Use of Laboratory Animals. The suffering and number of animals were minimized in all experimental procedures.

\section{Blocking protocol (TrkB-R, NMDA-R, CAMKII, and MAP-K)}

We randomly divided rats into 3-day exercise and sedentary control groups ( $n=5-8$ rats per group), pre-treated with antagonists or cytochrome C (Cyt.C), a standard control (Lom and Cohen-Cory, 1999). Any deviation in the amount of animals per group is due to animal death occurring during surgery, thus accounting for any reduction of eight to five animals per group.

We administered all drugs via injection of fluorescent latex microspheres directly into the right hippocampus, resulting in a consistent and effective blockade of targets as shown in the results. Previous studies by Quattrochi et al. (1989), Riddle et al. (1995, 1997), and Lom and Cohen-Cory (1999) have reported successful delivery by microspheres of bioactive agents such as neurotrophins and neurotransmitter agonists/antagonists into highly localized brain regions. Previous studies have also reported that using microspheres to insert neurotrophins has provided neurotrophic activity comparable to that of free neurotrophin and has retained activity for a period of at least 4 days (Riddle et al., 1997). Here we use this capability of microspheres to deliver antagonists for a period of 3 days.

The antagonists used consisted of k252a, a TrkB-R inhibitor, MK-801, an NMDA receptor antagonist, KN-62, a CAMKII inhibitor, and PD98059, a MAPK inhibitor. All these antagonists have been shown to effectively block or attenuate the action or expression of BDNF in vivo or in vitro; K252a application to hippocampal neurons has been shown to block BDNF-evoked rapid excitatory action (Kafitz et al., 1999); MK801 to block BDNF-enhanced synaptic transmission in hippocampal cultures (Levine et al., 1998); $\mathrm{KN}-62$ to attenuate seizure induced expression of BDNF mRNA in the adult rat brain (Murray et al., 1998); and PD98059 to abolish BDNF-triggered synaptic strengthening (Ying et al., 2002). Considering that the dose of K252a used by Kafitz et al. (1999) (150 nM) was applied by micropipettes or by a gravitation-based microperfusion system in vitro, we used $46.8 \mathrm{ng} / \mu \mathrm{l}$, a $1000 \times$ magnification of $100 \mathrm{nM}$ dose, to effectively block the action of BDNF in vivo. This amount was more consistent with the $100 \mathrm{ng} / \mu \mathrm{l}$ dose of neurotrophin used to coat microspheres for in vivo application (Riddle et al., 1997; Lom and Cohen-Cory, 1999). We used a dose of $12.5 \mu \mathrm{g} / \mu \mathrm{l}$ as indicated in Zhang et al. (2001) to block NMDA receptor-mediated processes in the rat hippocampus. For $\mathrm{KN}-62$, we used a dose of $7.2 \mu \mathrm{g} / \mu \mathrm{l}$ following the Wolfman et al. (1999) study in which KN-62 was used to effectively block CAMKII mediated memory of the water maze task. For PD98059, we used a dose of $1.33 \mathrm{ng} / \mu \mathrm{l}$, as directed in English and Sweatt (1997), in which it was employed to effectively block the action of MAPK and hippocampal LTP.

We prepared microspheres (Lumaflour, New York, NY, USA) by methods described previously by Riddle et al. (1997) and Lom and Cohen-Cory (1999). These consisted of coating the microspheres with each drug via passive absorbency by incubating overnight at $4{ }^{\circ} \mathrm{C}$ with a $1: 5 \mathrm{mix}$ of microspheres to k252a (46.8 $\mathrm{ng} / \mu \mathrm{l}$ sterile water; Kafitz et al., 1999), MK-801 (12.5 $\mu \mathrm{g} / \mu \mathrm{l}$ saline; Zhang et al., 2001), KN-62 (7.2 $\mu \mathrm{g} / \mu \mathrm{l}$ DMSO; Wolfman et al.,

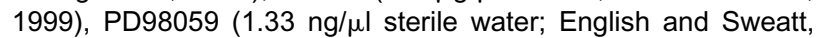
1997) or Cyt.C (100 ng/ $\mu$ l sterile water; Lom and Cohen-Cory, 1999). The morning after coating the microbeads, the solution was centrifuged at $14,000 \times \mathrm{g}$ for $30 \mathrm{~min}$ and the microbeads were resuspended in sterile water at a $10 \%$ concentration.

Exercise and sedentary rats received k252a, MK-801, KN-62, PD98059 or the standard control Cyt.C (Calbiochem Bioscience, La Jolla, CA, USA; Lom, 1999). All rats received the injections once prior to the 3 day running period, administered early in the morning, such that an ample recovery time permitted all animals to begin running that same evening. All animals were anesthetized (i.p.), once prior to receiving the drug injection, with a combination of $70 \mathrm{mg} / \mathrm{kg}$ of ketamine hydrochloride and $10 \mathrm{mg} / \mathrm{kg}$ of xylazine. We used a stereotaxic apparatus to secure the animal and measure the sight for microsphere injection. Microspheres were injected into the right hippocampus ( $3.8 \mathrm{~mm}$ from Bregma, $1 \mathrm{~mm}$ from the midline, and $3.7 \mathrm{~mm}$ vertically) with either $2 \mu \mathrm{l}$ of $\mathrm{k} 252 \mathrm{a}$, MK-801, KN-62, PD98059, or Cyt.C. The location of microbead injection was verified by histological examination of selected brains, as previously described (Quattrochi et al., 1989; Riddle et al., 1995). We visually inspected all the brains at the time of dissection, such that only those showing characteristic markings of microspheres of the right hippocampi were used. The microsphere injection site was additionally verified by florescence microscopy (shown in Fig. 2), using an Olympus BX51 microscope. Brain tissue was examined for BDNF, TrkB, CREB, and synapsin I mRNA using real-time quantitative reverse transcription polymer- 
ase chain reaction (RT-PCR; TaqMan RT-PCR EZ kit and Applied Biosystems prism model 7700 sequence detection instrument; Perkin-Elmer, Branchburg, NJ, USA) and corrected for GAPDH mRNA. Since many studies have found that the specificity of neurotrophin action is limited by the distribution of Trk-Rs (Thoenen, 1995; Heymach et al., 1996; Moller et al., 1998; Tongiorgi et al., 1997) and our study examines BDNF action through its TrkB-R, it was especially important to focus on the hippocampus, an area which expresses an abundance of BDNF and its receptor (Rocamora et al., 1996).

\section{Isolation of total RNA and real-time quantitative RT-PCR}

Total RNA was isolated using RNA STAT-60 kit (TEL-TEST, Inc., Friendswood, TX, USA) as per manufacturer's protocol. Quantification was carried out by absorption at $260 \mathrm{~nm}$. The mRNAs for BDNF, TrkB, NT-3, CREB and synapsin I were measured by real-time quantitative reverse transcription polymerase reaction (RT-PCR) using PE Applied Biosystems prism model 7700 sequence detection instrument (Applied Biosystems, Foster City, CA, USA), which directly detects the RT-PCR product without downstream processing. This is achieved by monitoring the increase in fluorescence of a dye labeled DNA probe, one that is specific for the factor of interest plus another specific for glyceraldyehyde-3-phosphate dehydrogenase (GAPDH) gene, which has been previously used as a successful endogenous assay control (Molteni et al., 2002a; Griesbach et al., 2002). Total RNA (100 ng) was converted into cDNA using TaqMan EZ RT-PCR Core reagents (Perkin-Elmer, Branchburg, NJ, USA). The sequences of probes, forward and reverse primers, designed by Integrated DNA Technologies (Coralville, IA, USA) were: BDNF: (5'-AGTCATTTGCGCACAACTTTAAAAGTCTGCATT-3'); forward: (5'-GGACATATCCATGACCAGAAAGAAA-3'); reverse: (5'-GCAACAAACCACAACATTATCGAG-3'); TrkB: (5'-TGC ACGTCTGGCCGCTCCTAACC-3'); forward: (5'-CCCAATTGTGGTCTGCCG-3'); reverse: (5'-CTTCCCTTCCTCCACCGTG-3'); CREB: (5'-CATGGCACGTAATGGAGACTACCGCA-3'); forward: (5'-CCGCCAGCATGCCTTC-3'); reverse: (5'-TGCAGCCCAATGACCAAA- $\left.3^{\prime}\right)$; synapsin I: (5'-CATGGCACGTAATGGAGACTACCGCA-3'); forward: (5'-CCGCCAGCATGCCTTC-3'); reverse: (5'-TGCAGCCCAATG ACCAAA-3'); NT-3: (5'-TGACCGACAAGTCCTCAGCCATTGAC-3'); forward: (5'-TGTGACAGTGAGAGCCTGTGG-3'); reverse: (5'-TGTAACCTGGTGTCCCCGAA-3'). The endogenous control probe, specific for the GAPDH gene, served to standardize the amount of RNA sample and consisted of the following oligonucleotide sequence (5'CCGACTCTTGCCCTTCGAAC-3'). The RT-reaction steps consisted of an initial $2 \mathrm{~min}$ incubation step at $50^{\circ} \mathrm{C}$ to activate uracil glycosylase (UNG) and were followed by $30 \mathrm{~min}$ of reverse transcription at $60{ }^{\circ} \mathrm{C}$. A completion step for UNG deactivation was performed for $5 \mathrm{~min}$ at $95^{\circ} \mathrm{C}$. The 40 cycles of two-step PCRreaction consisted of a $20 \mathrm{~s}$ period at $94{ }^{\circ} \mathrm{C}$ and a $1 \mathrm{~min}$ period at $62{ }^{\circ} \mathrm{C}$.

\section{Statistical analyses}

We used GAPDH for RT-PCR as an internal standard as described previously in our other studies (Molteni et al., 2002a, 2002). Quantification of the TaqMan RT-PCR results was performed by plotting fluorescent signal intensities against the number of PCR cycles on a semilogarithmic scale. A threshold cycle $\left(\mathrm{C}_{\mathrm{T}}\right)$ was designated as the amplification cycle at which the first significant increase in fluorescence occurred. The $C_{T}$ value of each sample was compared with that of the internal standard. These processes were fully automated and carried out using the $A B I$ sequence detector software version 1.6.3 (PE Biosystem). Taqman EZ RT-PCR values for BDNF, TrkB, CREB, synapsin I, and NT-3 were corrected by subtracting values for GAPDH as

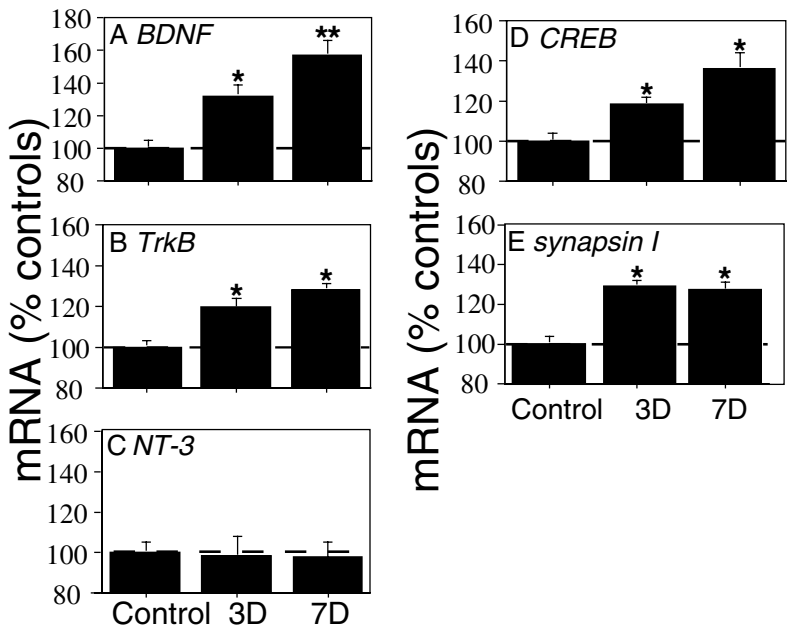

Fig. 1. Effect of exercise on the level of BDNF mRNA and its TrkB receptor in the hippocampus, by day 3 (3D) and day 7 (7D), relative to sedentary controls. (A) BDNF mRNA levels significantly increase by day $3(132 \% ; P<0.05)$ and day $7(157 \% ; P<0.01)$. (B) TrkB mRNA levels significantly increase $(P<0.05)$ by day $3(119 \%)$ and day 7 $(128 \%)$. (C) NT-3 mRNA levels show no trend or significance of increase at 3 and 7 days of exercise. Effect of exercise on the mRNA levels of CREB and synapsin I, in the hippocampus by day 3 (3D) and day 7 (7D), relative to sedentary controls. (D) CREB mRNA levels significantly increase $(P<0.05)$ by day $3(118 \%)$ and day $7(136 \%)$. $(E)$ Synapsin I mRNA levels significantly increase $(P<0.05)$ by day 3 $(129 \%)$ and remain so on day $7(127 \%)$. Each value represents the mean \pm S.E.M. $\left({ }^{*} P<0.05,{ }^{* *} P<0.01\right.$; ANOVA, Fischer-test).

previously described (Molteni et al., 2002a; Griesbach et al., 2002). These corrected values were used to make cross-group comparisons. The mean values for the mRNA levels were computed for the control (sedentary) and exercise groups after 3 and 7 days of exercise and for the 3 day Cyt.C control and exercise groups which received surgical intervention and compared using ANOVA. The mean values of distances (kilometers) run over 3 days of exercise were computed for each of the surgical intervention groups and compared using ANOVA. A Fischer-test was used for cross-group comparisons. Results were expressed as the mean percent of control values for graphic clarity and represent the mean \pm S.E.M. of five to eight independent determinations. To evaluate association between variables, TrkB and synapsin I mRNA, a linear regression analysis was performed on individual samples which were randomly chosen $(n=20)$ from all the surgical intervention groups. To evaluate association between synapsin I mRNA and total distance run in a 3 day period, we used only the Cyt.C. exercise controls $(n=8)$, since this group had both the exercise component and abstinence from an inhibitor, whose presence could potentially alter synapsin I mRNA levels.

\section{RESULTS}

\section{Effects of exercise on the mRNA levels of BDNF and its TrkB-R}

BDNF uses TrkB as the primary receptor to transduce activity into signal transduction cascades (Barbacid, 1994). Accordingly, we quantified hippocampal TrkB as well as BDNF mRNA levels in animals exercised for 3 and 7 days. Not only did we find significant increases for BDNF mRNA after days $3(132 \%, P<0.05)$ and $7(157 \%, P<0.01$; Fig. $1 A)$ of exercise, but we also concurrently found significant $(P<0.05)$ increases in the mRNA of its signal transduction 


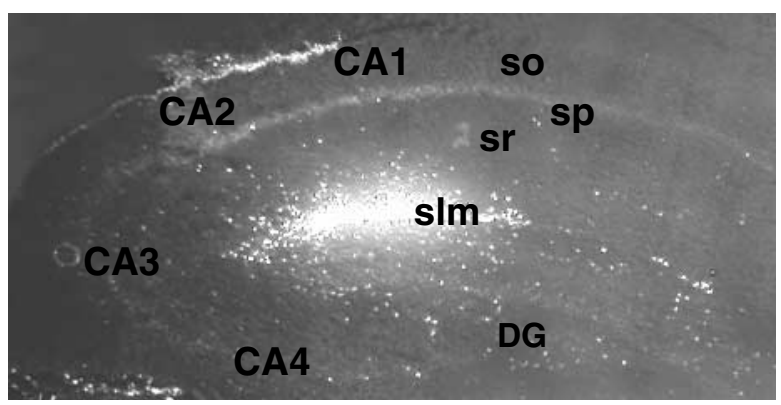

Fig. 2. Tissue section in the sagittal plane showing the microbead injection site, concentrated in the stratum lacunosum-moleculare of the right hippocampus using fluorescence microscopy. Hippocampal areas have been labeled; CA1, CA2, CA3, and dentate gyrus (DG) as well as a division of the hippocampus proper into so (stratum oriens), $\mathrm{sp}$ (stratum pyramidale), sr (stratum radiatum), and slm (stratum lacunosum-moleculare).

receptor, TrkB, after $3(119 \%)$ and 7 days of exercise (128\%; Fig. 1B).

To evaluate whether the effects of exercise are selective for BDNF, we measured the mRNA levels of NT-3, another member of the neurotrophin family expressed in hippocampal neurons. Our results showed no changes in NT-3 mRNA levels after 3 and 7 days of exercise (Fig. 1C).

\section{Effect of exercise on plasticity markers: CREB and synapsin I mRNA levels}

We found that CREB mRNA levels increase significantly $(P<0.05)$ after $3(118 \%)$ and $7(136 \%)$ days of exercise (Fig. 1D). Likewise, synapsin I mRNA levels in the hippocampus showed a significant $(P<0.05)$ increase by days $3(129 \%)$ and $7(127 \%)$ of exercise, relative to controls (Fig. 1E).

\section{Microbead injection site}

We inspected the microbead injection location via fluorescence imaging. As shown in Fig. 2, the location of the microbead injection site was concentrated in the stratum lacunosum-moleculare. Our microbead infusion site is consistent with other previous drug infusion protocols, which either evaluated the effect of inhibitors (Zhang et al., 2001; Blum et al., 1999; Kawabe et al., 1998) or exogenous BDNF (Messaoudi et al., 2002) on hippocampal function. Additionally, the use of microbeads may supersede the use of more invasive injection techniques such as cannula injection. The location of the microbead injection site shows only the location and size of the microbead injection (Fig. 2). With the use of microbeads, the microbead carrier is centralized to the injection site, while the drug transported is free to disperse to other areas of the hippocampus.

\section{Effect of blocking the Trk receptor on hippocampal BDNF, TrkB, CREB, and synapsin I mRNA levels (Fig. 3A; Table 1)}

In order to determine the involvement of BDNF action through the Trk-R in the pathways through which exercise regulates synapsin I, BDNF, TrkB and CREB mRNA levels, we used k252a (46.8 ng/ $\mu \mathrm{l})$, which has been shown to block the action of BDNF through the TrkB-R in the hippocampus in vitro (Kafitz et al., 1999).

We found that k252a consistently and completely abolished the exercise-induced increases in all the mRNAs measured, i.e. BDNF $(P<0.05)$, TrkB $(P<0.05)$, CREB $(P<0.01)$, and synapsin I $(P<0.05)$. We found that $\mathrm{k} 252 \mathrm{a}$ did not significantly modify the sedentary mRNA levels of BDNF, TrkB and synapsin I. On the other hand, k252a selectively and vigorously reduced $(P<0.05)$ the sedentary levels of CREB mRNA.

\section{Effect of blocking the NMDA-R on hippocampal BDNF, TrkB, CREB, and synapsin I mRNA levels (Fig. 3B; Table 1)}

The NMDA-R plays a critical role in neuronal plasticity (Bliss and Collingridge, 1973; Cammarota et al., 2000), and has a well-established interaction with both MAP-K (Platenik et al., 2000) and BDNF (Suen et al., 1997). Therefore, we examined the possibility that the NMDA-R is involved in pathways through which exercise increases the hippocampal mRNA levels of BDNF, TrkB, CREB, and synapsin I. We measured mRNA levels while blocking the NMDA-R with MK-801 at a dose of $12.5 \mu \mathrm{g} / \mu \mathrm{l}$, following the dosage used by Zhang et al. (2001), which completely prevented the exercise-induced increases in all the mRNAs measured: BDNF $(P<0.05)$, TrkB $(P<0.01)$, CREB $(P<0.05)$, and synapsin I $(P<0.01)$.

MK-801 also dramatically curtailed $(P<0.01)$ sedentary TrkB and synapsin I mRNA levels. In addition, MK-801 managed to significantly $(P<0.05)$ attenuate BDNF mRNA during the sedentary condition. Conversely, MK-801 did not significantly decrease CREB mRNA levels during the sedentary condition.

Effect of blocking CAMKII on hippocampal BDNF, TrkB, CREB, and synapsin I mRNA levels (Fig. 3C; Table 1)

CAMKII has been demonstrated to potentiate synaptic efficacy (Bayer et al., 2001; McGlade-McCulloh et al., 1993). Since CAMKII can be activated through the NMDA-R to converge on the MAP-K cascade, we sought to determine if CAMKII also mediated the effects of exercise on BDNF, CREB, TrkB, and synapsin I mRNA levels. To determine its involvement, we used $\mathrm{KN}-62$ to specifically block CAMKII (Wolfman et al., 1999) at a dose of $7.2 \mu \mathrm{g} / \mu \mathrm{l}$, since KN62 has been shown to attenuate the characteristic induction of BDNF mRNA in adult rat brain following seizure activity (Murray et al., 1998). The dosage used in our study was similar to the dosage used by Wolfman et al. (1999), in which it was used to block CAMKII and its effect on hippocampal necessitated memory task in rats. Here we show that $\mathrm{KN}-62$ effectively prevents the exercise-induced increases of all the mRNAs measured as described below.

We found that KN-62 completely abolished $(P<0.05)$ the exercise induced increases in TrkB and synapsin I mRNA levels. KN-62 also significantly $(P<0.05)$ stamped 


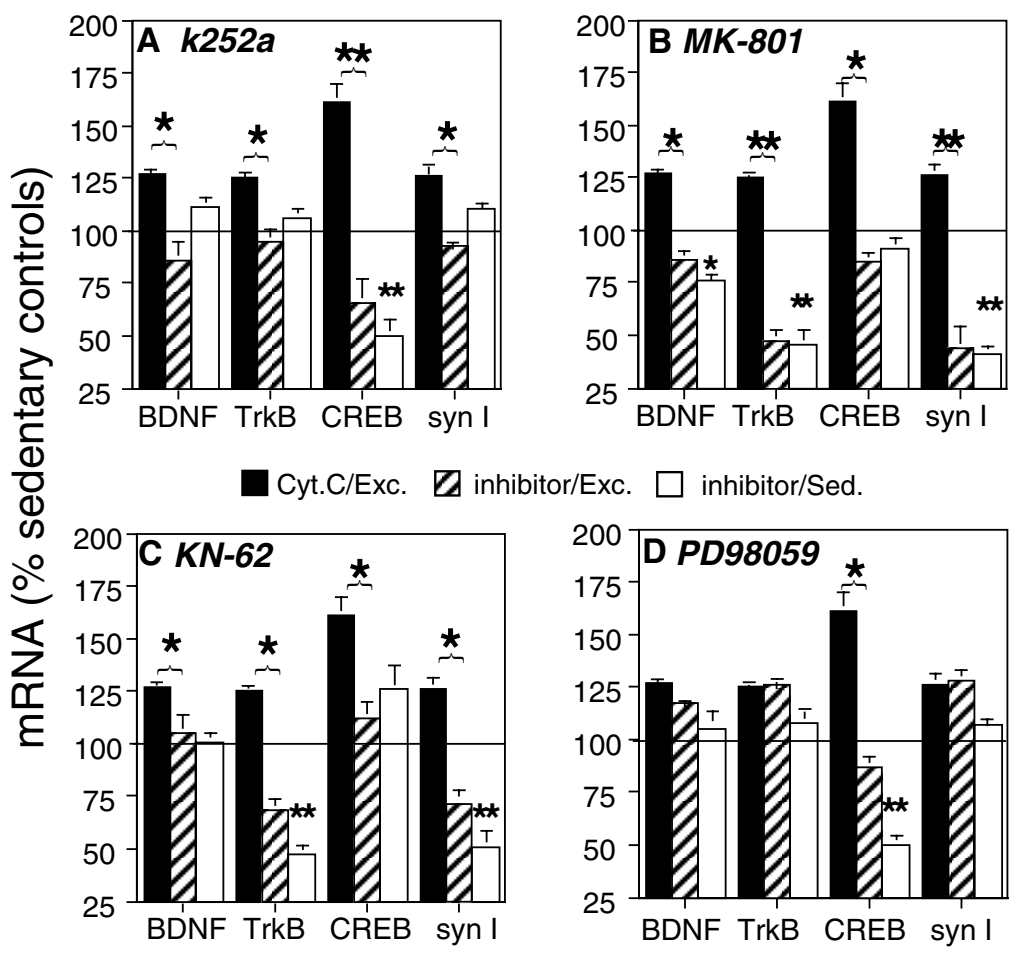

Fig. 3. Effects of various blocking agents (inhibitors) on the mRNA levels of BDNF, TrkB, CREB, and synapsin I in the hippocampus after 3 days of voluntary exercise (inhibitor/Exc.). Results are displayed as percentage of sedentary controls (Sed.). (A) mRNA levels in sedentary and exercise animals in the presence and absence of the Trk-R blocker k252a. All exercise-induced increases are completely abolished with k252a; reducing BDNF, TrkB, CREB, and synapsin I mRNA levels. Only CREB mRNA levels were significantly $(P<0.05)$ reduced $(50 \%)$ in sedentary rats. (B) mRNA levels in sedentary and exercise animals in the presence and absence of MK-801, a non-competitive NMDA-R blocker. All exercise-induced increases are completely abolished in the presence of MK-801; reducing BDNF, TrkB, CREB, and synapsin I. Significant reduction in mRNA levels of BDNF, TrkB, and synapsin I during the sedentary condition. (C) mRNA levels of sedentary and exercise animals in the presence and absence of KN-62, a selective CAMKII inhibitor. All exercise-induced increases are completely abolished $(P<0.05)$ in the presence of KN-62; reducing BDNF, TrkB, CREB, and synapsin I mRNA levels. Significant $(P<0.05)$ reduction in mRNA levels of TrkB and synapsin I during the sedentary condition. (D) mRNA levels of sedentary and exercise animals in the presence and absence of PD98059, an inhibitor of MAP-K. Exercise-induced increases in CREB mRNA levels were fully and significantly $(P<0.05)$ reduced, while BDNF mRNA levels showed a non-significant decrease. Sedentary CREB mRNA levels were selectively reduced $(50 \% ; P<0.01)$. Cyt.C/Sedentary controls are represented by the $100 \%$ horizontal line such that the statistical significance of mRNA levels for inhibitor/Sed. animals is represented as compared with this line. A bracket (\}) is placed to compare significance between Cyt.C/Exc. and inhibitor/Exc. Groups. Each value represents the mean \pm S.E.M. ( ${ }^{*} P<0.05,{ }^{* *} P<0.01$; ANOVA, Fischer-test).

out the bulk of the exercise-induced increase in BDNF and CREB mRNA levels. In addition, we also found that KN-62 consistently and significantly $(P<0.01)$ attenuated the sedentary levels of TrkB and synapsin I mRNAs. Conversely, we found that $\mathrm{KN}-62$ did not reduce the sedentary mRNA levels of BDNF. To our surprise, KN-62 application produced an apparent increasing, albeit insignificant, tendency in sedentary CREB mRNA levels.

\section{Effect of blocking MAP-K on hippocampal BDNF, TrkB, CREB mRNA, and synapsin I levels (Fig. 3D; Table 1)}

It is well known that MAP-K plays a role in synaptic plasticity (English and Sweatt, 1997). Besides its interaction with BDNF (Ying et al., 2002; Jovanovic et al., 1996) and the NMDA-R (Platenik et al., 2000), it is notable for regulating CREB (Finkbeiner et al., 1997) and synapsin I (Jovanovic et al., 1996). Therefore, we wanted to evaluate the possibility that MAP-K may be involved in pathways through which exercise increases the mRNA levels of
BDNF, TrkB, CREB, and synapsin I. Accordingly, we blocked the MAP-K cascade with PD98059 and measured the effect on these mRNA levels. The dose of PD98059 used in our study has been shown to block the action of MAP-K and its mediation of hippocampal LTP in vivo (English and Sweatt, 1997). Here PD98059 effectively prevented the exercise-induced elevation of CREB mRNA levels.

We found that PD98059 application in exercised animals did not significantly change the mRNA for synapsin I and TrkB from that of the exercise/Cyt.C animals. Conversely, PD98059 completely abrogated $(P<0.05)$ the exercised-induced increase in CREB mRNA levels below sedentary controls and attenuated, noticeably albeit insignificantly, the exercise-induced increase in BDNF mRNA levels.

In addition, we found that PD98059 implementation in sedentary animals did not change the mRNA levels of synapsin I, TrkB, or BDNF from those of Cyt. C. sedentary controls, but significantly $(P<0.01)$ decreased CREB mRNA levels. 
Table 1. Numerical summary of graphical group data presented in Fig. $3^{\mathrm{a}}$

\begin{tabular}{lllll}
\multicolumn{2}{l}{ Drugs administered } & & & \\
\hline Cytc. $\quad$ K252a & MK-801 & KN-62 & PD98059
\end{tabular}

(A) mRNA levels as percentage of sedentary controls under various drug applications, in animals after 3 days of exercise

$\begin{array}{llllrc}\text { BDNF } & 127 \pm 2 & 86 \pm 9^{*} & 86 \pm 4^{*} & 105 \pm 9^{*} & 117 \pm 2 \\ \text { CREB } & 161 \pm 9 & 66 \pm 11^{* *} & 85 \pm 4^{*} & 112 \pm 8^{*} & 87 \pm 5^{*} \\ \text { TrkB } & 125 \pm 2 & 95 \pm 6^{*} & 47 \pm 6^{* *} & 68 \pm 6^{*} & 126 \pm 3\end{array}$

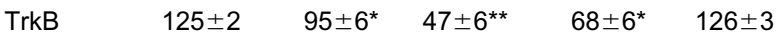

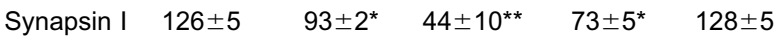

(B) mRNA levels as percentage of sedentary controls under various drug applications, in sedentary animals after 3 days

$\begin{array}{llllll}\text { BDNF } & 100 \pm 7 & 111 \pm 5 & 76 \pm 3^{*} & 101 \pm 4 & 105 \pm 7\end{array}$

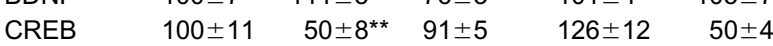

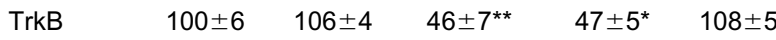

Synapsin I $100 \pm 4 \quad 110 \pm 3 \quad 41 \pm 4^{* *} \quad 51 \pm 8^{*} \quad 107 \pm 2$

a (A) mRNA levels as percentage of sedentary controls under various drug applications following 3 days of exercise; the statistical significance of mRNA levels for the inhibitor/Exc. groups is represented as compared to the Cyt.C/Exc. group. (B) mRNA levels as percentage of sedentary controls under various drug applications, in sedentary animals after 3 days; the statistical significance of the mRNA levels for the inhibitor/Sed. groups is represented as compared to the Cyt.C/Sedentary control. Data are expressed as mean \pm S.E.M. $\quad\left({ }^{*} P<0.05\right.$, ** $P<0.01$; ANOVA, Fischer-test).

\section{Synapsin I and TrkB mRNA levels; effect of exercise and inhibitors}

We found that synapsin I and TrkB mRNA levels exhibited replicate responses to all inhibitors used (Fig. 4A, B). BDNF-mediated activation of presynaptic TrkB-R is coupled to the regulation of synapsin I (Jovanovic et al., 2000). Accordingly, we evaluated the possibility that changes in
TrkB are associated to changes in synapsin I during exercise. A correlation analysis between synapsin I and TrkB mRNA levels in the hippocampus following 3 days of exercise showed that synapsin I and TrkB mRNA levels exhibit a high positive correlation $(r=0.882, P<0.01$; Fig. 4C).

We found that the average distance (kilometers) run over a 3 day period did not significantly vary across groups; Cyt C. (1.40 \pm 0.38$),$ k252a (1.70 \pm 0.36$)$ MK-801 $(1.67 \pm 0.42), \quad \mathrm{KN}-62 \quad(1.61 \pm 0.53), \quad$ and PD98059 $(1.54 \pm 0.50)$. To determine if the amount of exercise is predictive of the amount of synapsin I mRNA increase, we performed a regression analysis on the total distance run over a 3-day period and synapsin I mRNA levels. Although all exercise groups exhibited similar distances run over a 3 day period, we used the Cyt.C exercise group since it was free of any inhibitor application which could alter synapsin I mRNA levels and thereby obscure the presence of a relationship between distance run and synapsin I mRNA levels. We found a significant positive correlation between synapsin I mRNA and total distance run $(r=0.845, P<0.01$; Fig. 4D).

\section{DISCUSSION}

The salutary effect of exercise on neural function, although well documented (Laurin et al., 2001; van Praag et al., 1999a), remains for the most part unexplored in its underlying mechanisms. Recently, studies have suggested the possibility that BDNF may be one of the molecules mediating exercise's ability to endow neural-plasticity to the adult brain. Here we show that, in the hippocampus, an area critical for learning and memory formation, voluntary
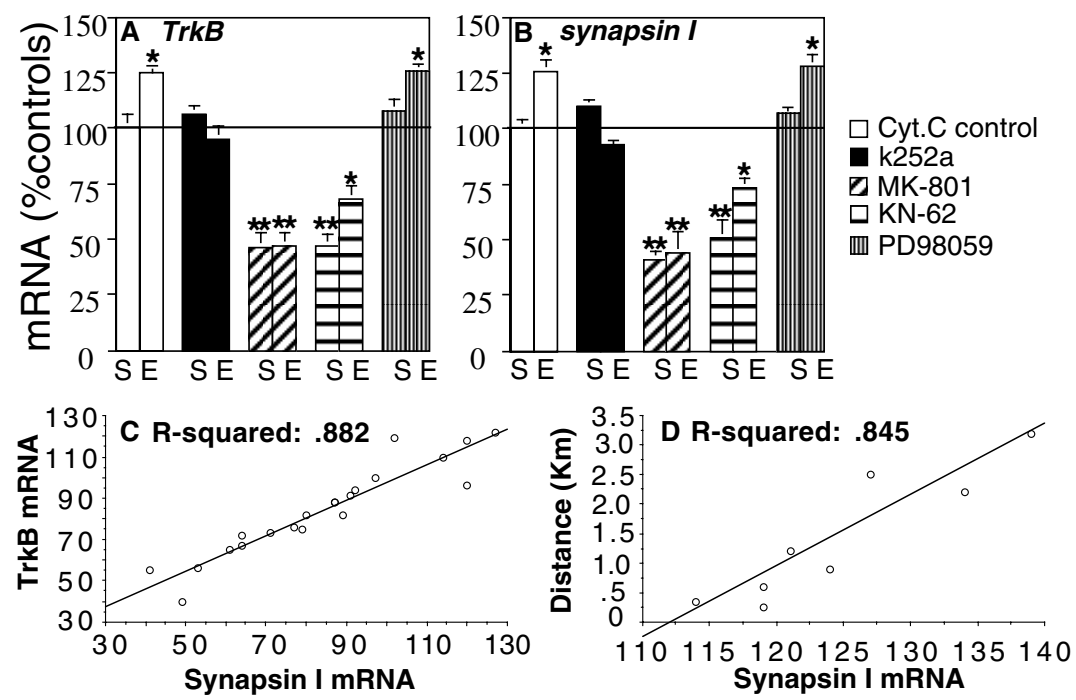

Fig. 4. TrkB and synapsin I mRNA levels showing analogous responses to all inhibitors used after 3 days of exercise. mRNA levels of TrkB (A) and synapsin I (B) in the exercise (E) and sedentary (S) conditions, showing their analogous response to the presence of all inhibitors used, i.e. k252a, PD98059, MK-801, KN-62, as well as Cyt.C control. Statistical significance for groups is represented as compared with the $100 \%$ line. Each value represents the mean \pm S.E.M. ( ${ }^{*} P<0.05,{ }^{* *} P<0.01$; ANOVA, Fischer-test). (C) Correlation analysis of exercise-induced TrkB and synapsin I mRNA levels after 3 days of exercise, using random samples $(n=20)$ from all surgical intervention groups. Synapsin I mRNA and TrkB mRNA levels are positively correlated $(r=0.882, P<0.01)$. (D) Synapsin I mRNA levels and total distance after a 3 day exercise period, using the Cyt.C exercise controls $(n=8)$, show a significant positive correlation $(r=0.845, P<0.01)$. 


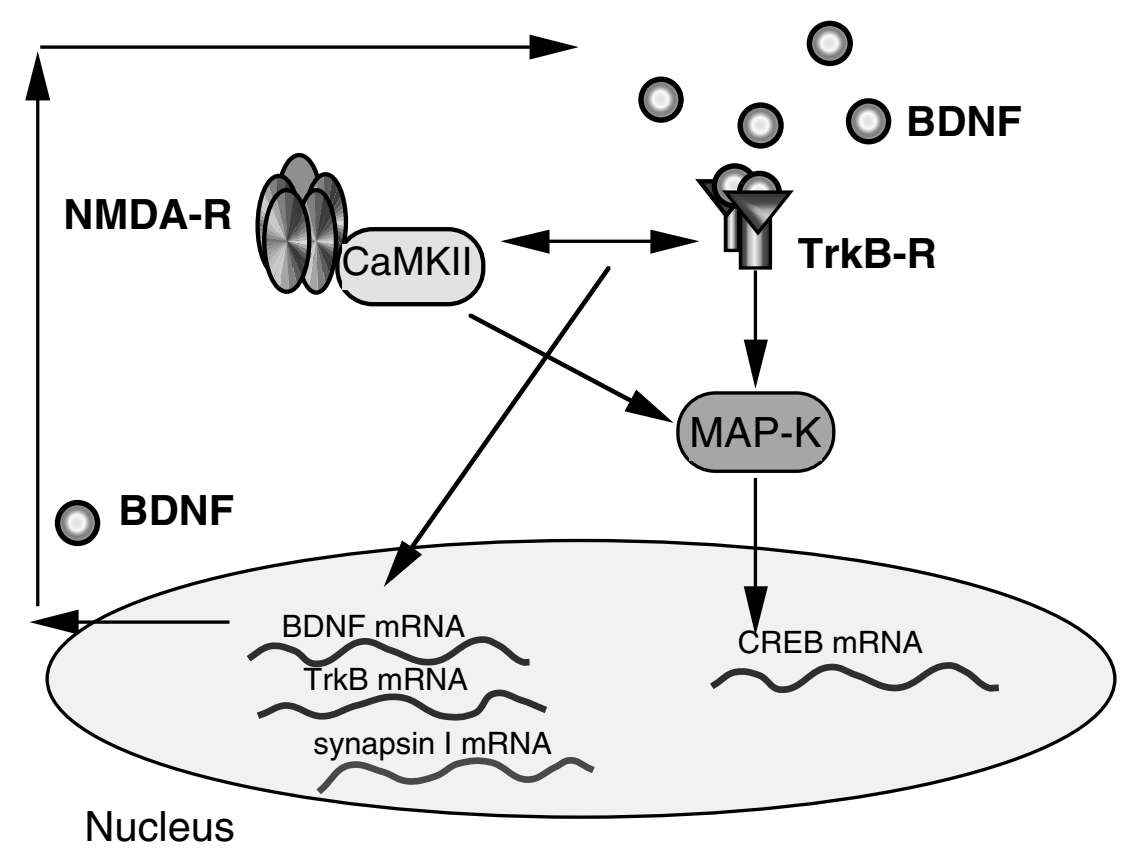

Fig. 5. Diagram of proposed basic mechanism, by which exercise can affect the synapse, using BDNF as a central player. Exercise may engage both BDNF and the NMDA-R, possibly by employing BDNF to potentiate transmission through the NMDA-R. Furthermore, exercise may activate BDNF through the TrkB-R and the NMDA-R, acting through CAMKII, to converge on the MAP-K cascade. The CAMKII-MAP-K pathway may be important for the regulation of CREB mRNA levels during exercise. In contrast, BDNF may interact with the NMDA-R to regulate the exercise-induced mRNA levels of BDNF, TrkB, and synapsin I, by employing CAMKII without MAP-K activation. The importance of BDNF as a central player of the effects of exercise is noteworthy given the fact that since exercise increases both BDNF mRNA and proteins levels, BDNF may have the ability to maintain the effects of exercise on synaptic plasticity by a self-perpetuating loop.

exercise not only elevates the expression of BDNF (Fig. $1 \mathrm{~A})$, but also is the means through which BDNF can exert its action on neural-plasticity, i.e. an increase in its signal transduction receptor, TrkB-R (Fig. 1B). Additionally, exercise increases the expression of molecules both involved in synaptic-plasticity and associated to the action of BDNF, i.e. CREB and synapsin I (Fig. 1D, E). Most refreshingly, having identified potential modulators for the effects of exercise on synaptic-plasticity by using a novel microsphere infusion system, i.e. the NMDA-R, and CAMKII for all mRNAs measured, and MAP-K for CREB (Fig. 5), this study provides the initial framework toward elucidating the possible signaling pathways through which exercise may benefit neural function.

The role of BDNF: modulation of exercise-induced changes in the mRNA levels of BDNF, TrkB, CREB, and synapsin I

Our results show that k252a fully abolished the exerciseinduced increase in all mRNAs measured, i.e. BDNF, TrkB, CREB, and synapsin I (Fig. 3A). Although k252a is selective for the Trk family (Knusel and Hefti, 1992), (1) the absence of TrkA-Rs in hippocampal neurons (Kang and Schuman, 1995; Merlio et al., 1992), and (2) the invariable post-exercise mRNA levels of NT-3 (Fig. 2C), which preferentially binds to the TrkC-R (Barbacid, 1994), propounds that the TrkB-R is most likely blocked. Consequentially, BDNF is the most likely neurotrophin whose action is obstructed, not only because it bears a superlative affinity for the TrkB-R (Kafitz et al., 1999), but also because NT-4/5, which although it has a high affinity for the TrkB-R, is scarce in the hippocampus (Friedman et al., 1998; Timmusk et al., 1993). Furthermore, K252a has been shown to block the BDNF-evoked excitatory potentials in hippocampal neurons (Kafitz et al., 1999). Thus, our finding, that blocking the Trk-R completely abolished the exercise-induced increases in TrkB and BDNF mRNA levels, provides the interesting corollary, that BDNF very likely contributes to regulate itself and its receptor during exercise. Accordingly, a decrease in BDNF action may account for decreases in CREB and synapsin I mRNAs, during exercise. These conclusions are further supported by finding that k252a extirpates functions consigned to BDNF, i.e. TrkB-R and CREB phosphorylation and transcription of early genes (Watson et al., 1999).

The role of the NMDA-R and CAMKII; modulation of exercise-induced changes in the mRNA levels of BDNF, TrkB, CREB, and synapsin I

Given the critical roles the NMDA-R plays in neural-plasticity: modulation of LTP (Bliss and Collingridge, 1973), mediating learning and memory processes (Cammarota et al., 2000), and regulating synaptogenesis (Hollmann et al., 1994), we anticipated its participation in regulating exercise-induced mRNA levels. However, it was unexpected that, just as in the case of the TrkB-R, blocking the NMDA-R was sufficient to fully abrogate the exerciseinduced increases in all mRNAs measured, i.e. BDNF, 
TrkB, CREB, and synapsin I (Fig. 3A vs. 3B). Thus, the activity-dependent action of BDNF may depend on an interaction with the NMDA-R, which in turn possibly interacts with other signaling molecules. CAMKII is likely one of these molecules, since blocking its action fully abolished the exercised-induced increases in synapsin I and TrkB mRNA levels, and efficaciously decreased the mRNA levels of CREB and BDNF (both $>80 \%$; Fig. $3 \mathrm{C}$ ). Moreover, the NMDA-R is extremely proficient at binding CAMKII at the synapse (Bayer et al., 2001). CAMKII participates in mechanisms underlying learning and memory (Yin and Tully, 1996) and has the ability to remain autonomously operative after its activating $\mathrm{Ca}^{2+}$ stimulus has waned (Bayer et al., 2001). This capacity may act to prolong the effects of exercise on synaptic-plasticity.

\section{The role of MAP-K: modulation of CREB mRNA levels}

Our results were particularly interesting regarding CREB and MAP-K. CREB is one of the best-described stimulusinduced transcription factors involved in adaptive responses and long-term memory (Finkbeiner, 2000). Similarly, MAP-K promotes a wide range of plasticity changes: nuclear signaling (Adams et al., 2000), LTP (English and Sweatt, 1997), and learning and memory formation (Blum et al., 1999). In fact, the capacity of MAP-K to induce long-lasting changes in synaptic-plasticity is attributed to its ability to regulate (Finkbeiner et al., 1997), and prolong the transcriptionally active state of CREB (Hardingham et al., 2001). Thus, it is interesting that CREB was the only molecule whose exercise-induced increase in mRNA levels was completely abrogated by blocking MAP-K (Fig. 3D). This may indicate an additional ability of MAP-K to regulate CREB transcription. More likely, since CREB uses a CRE sequence on its promoter region to regulate its own gene expression (Meyer et al., 1993; Tao et al. 1998), MAP-K phosphorylation of CREB (Hardingham et al., 2001), may function to increase CREB mRNA levels during exercise. In fact, other recent findings have shown that BDNF mRNA levels increase and that both CREB and MAPK are activated during exercise (Shen et al., 2001; Molteni et al., 2002b). The finding of an insignificant yet noticeable $37 \%$ decrease in BDNF mRNA levels during MAP-K inhibition (Fig. 3D) further supports this interpretation. Since phospho-CREB can activate BDNF transcription (Finkbeiner, 2000), this decrease may be a secondary effect of blocking MAP-K phosphorylation of CREB. We found larger levels of CREB mRNA in exercise animals who have undergone surgery. This effect was not seen with BDNF, TrkB, and synapsin I mRNA levels and may possibly be due to injury, which has been shown to increase activation of CREB (Walton et al., 1996). This effect of injury was for all purposes standardized by using a Cyt.C. control group (as represented by the 100\% line in Figs. 3 and 4), thus enabling us to see an effect of blocking the various signaling molecules.

Singularly blocking the TrkB-R, the NMDA-R, CAMKII, or MAP-K (Fig. 3A-D) was sufficient to completely abrogate the exercise-induced increases in the mRNA levels of
CREB. Thus, all these signaling molecules may interact in a common pathway, upstream to changes in CREB mRNA levels (Fig. 5). Although the exact relationship is unknown, BDNF has been demonstrated to potentiate synaptic transmission through the NMDA-R (Song et al., 1998). Furthermore, BDNF through its TrkB-R (Jovanovic et al., 1996), and the NMDA-R through CAMKII (Platenik et al., 2000), can both converge on MAP-K. Blocking CAMKII does not decrease CREB mRNA levels in the sedentary condition (Fig. 3C). Thus, the CAMKII-MAP-K pathway may become more relevant during exercise.

\section{Modulation of synapsin I mRNA levels}

Finding that TrkB and synapsin I mRNA levels (1) exhibit a high positive correlation ( $r=0.882, P<0.01$; Fig. $4 \mathrm{C}$ ) and (2) replicate responses to all inhibitors used, targeting BDNF, the NMDA-R, and CAMKII (Fig. 4A, B respectively), suggests a common mode of regulation. Additionally, blocking either the NMDA-R or CAMKII, during the sedentary condition, decreased synapsin I and TrkB mRNA levels (Figs. 3B, C and $4 A, B$ respectively), indicating that both may participate in modulating sedentary TrkB and synapsin I mRNA levels.

Studies have shown that BDNF action through its TrkB-R is coupled with presynaptic neurotransmitter release via MAP-K phosphorylation of synapsin I (Jovanovic et al., 2000). Our finding that inhibiting BDNF action abrogates the exercise-induced increase in synapsin I mRNA levels propounds that the role of BDNF may extend to synapsin I mRNA regulation during exercise. Additionally, the finding that inhibiting CAMKII but not MAP-K abolished the exercise-induced increase in synapsin I mRNA levels suggests the involvement of CAMKII instead of MAP-K in synapsin I mRNA regulation. This does not exclude the possibility that during exercise, synapsin I may be regulated by BDNF on another level, such as MAP-K-mediated synapsin I phosphorylation (Jovanovic et al., 1996).

Since synapsin I tethers synaptic vesicles (SV) to the actin cytoskeleton only after their advent at the terminal (Greengard et al., 1993), the increase in synapsin I mRNA levels, as a result of exercise, may be indicative of an increase in the rate of SV formation. The provision of a substantial localized SV reserve pool is necessary to prevent vesicular rundown during high frequency stimulation (Pieribone et al., 1995). In fact, inhibiting synapsin I reduces both the SV reserve pool and neurotransmitter release (Hilfiker et al., 1999). Interestingly, synaptic fatigue has been shown to result from blocking BDNF action (Pozzo-Miller et al., 1999), which, according to our results, may be due to a decrease in synapsin I mRNA levels. Therefore, the significant increase in synapsin I mRNA levels may be functionally important for the establishment of a SV reserve pool during exercise. It is logical that exercise, in which rats run extensively (on average 1.5 $\mathrm{km} / 3$ days), would provide sufficient stimulation to compel an increase in the rate of SV formation. In fact, the amount of exercise is predictive of synapsin I mRNA levels (Fig. 4D). 


\section{CONCLUSIONS}

Recent studies have reported that BDNF mRNA, activation of CREB and MAPK in the hippocampus by exercise may play a role in exercise-triggered neural plasticity. The results of this study have not only characterized exerciseinduced changes in synaptic-plasticity, but have also furthered the understanding of how these mediators may interact to enable exercise to promote changes in synapticplasticity. While BDNF plays a critical role in regulating exercise-induced changes in synaptic-plasticity, we found evidence to indicate that its interaction with other molecules i.e. the NMDA-R, CAMKII, and MAP-K, may significantly modulate its effects. Overall, evidence indicates that exercise may contribute to promoting and maintaining neuronal function through a neurotrophin-mediated mechanism, especially since our findings indicate that exercise may employ BDNF in a self-perpetuating loop (Fig. 5). Moreover, this mechanism appears to affect molecules associated with gene-transcription regulation and synaptic-function. The preponderance of BDNF in behaviors, which promote learning and memory, antagonize age-related cognitive deficits, and/or facilitate functional-recovery from brain injury and disease, implores its further investigation. The more detail we learn about the pathways underlying synaptic-plasticity, the closer we will come to finding multiple avenues, some of which may include BDNF, for therapeutic intervention. Exercise, via a BDNF-mediated mechanism, may be one road taken to promote synaptic-plasticity in the adult hippocampus.

Acknowledgements-We wish to thank Dr. R. Molteni for critical comments on the manuscript and Dr. D. Yin for his assistance with surgeries. This study was supported by NIH awards NS 38978 and NS 39522.

\section{REFERENCES}

Adams J, Roberson ED, English JD, Selcher JC, Sweatt JD (2000) MAPK regulation of gene expression in the central nervous system. Acta Neurobiol Exp 60:377-394.

Bading H, Greenberg ME (1991) Stimulation of protein tyrosine phosphorylation by NMDA receptor activation. Science 253:912-914.

Baekelandt V, Arckens L, Annaert W, Eysel UT, Orban GA, Vandesande $F$ (1994) Alterations in GAP-43 and synapsin immunoreactivity provide evidence for synaptic reorganization in adult dorsal later geniculate nucleus following retinal lesions. Eur $\mathrm{J}$ Neurosci 6:754-765.

Barbacid M (1994) The Trk family of neurotrophin receptors. J Neurobiol 25:1386-1403.

Barde YA (1994) Neurotrophins: a family of proteins supporting the survival of neurons. Prog Clin Biol Res 390:45-56.

Bayer KU, De Koninck P, Leonard AS, Hell JW, Schulman H (2001) Interaction with the NMDA receptor locks CaMKII in an active conformation. Nature 411:801-805.

Bliss TVP, Collingridge GL (1973) A synaptic model of memory: longterm potentiation in the hippocampus. Nature 361:31-39.

Blum S, Moore AN, Adams F, Dash PK (1999) A mitogen-activated protein kinase cascade in the CA1/CA2 subfield of the dorsal hippocampus is essential for long-term spatial memory. J Neurosci 19:3535-3544.

Cammarota M, de Stein ML, Paratcha G, Bevilaqua LR, Izquierdo I, Medina JH (2000) Rapid and transient learning-associated in- crease in NMDA NR1 subunit in the rat hippocampus. Neurochem Res 25:567-572.

Curtis R, Tonra JR, Stark JL, Adryan KM, Park JS, Cliffer KD, Lindsay RM, DiStefano PS (1999) Neuronal injury increases retrograde axonal transport of the neurotrophins to spinal sensory neurons and motor neurons via multiple receptor mechanisms. Mol Cell Neurosci 12:105-118.

English JD, Sweatt JD (1997) A requirement for the mitogen-activated protein kinase cascade in hippocampal long term potentiation. J Biol Chem 272:19103-19106.

Figurov A, Pozzo-Miller LD, Olafsson P, Wang T, Lu B (1996) Regulation of synaptic responses to high-frequency stimulation and LTP by neurotrophins in the hippocampus. Nature 381:706-709.

Finkbeiner S (2000) CREB couples neurotrophin signals to survival messages. Neuron 25:11-14.

Finkbeiner S, Tavazoie SF, Maloratsky A, Jacobs KM, Harris KM, Greenberg ME (1997) CREB: a major mediator of neuronal neurotrophin responses. Neuron 19:1031-1047.

Fordyce DE, Wehner JM (1993) Physical activity enhances spatial learning performance with an associated alteration in hippocampal protein kinase $\mathrm{C}$ activity in C57BL/6 and DBA/2 mice. Brain Res 619:111-119.

Friedman WJ, Black IB, Kaplan DR (1998) Distribution of the neurotrophins brain-derived neurotrophic factor, neurotrophin-3, and neurotrophin- $4 / 5$ in the postnatal rat brain: an immunocytochemical study. Neuroscience 84:101-114.

Ghosh A, Ginty DD, Bading H, Greenberg ME (1994) Calcium regulation of gene expression in neuronal cells. J Neurobiol 25:294303.

Grealy MA, Johnson DA, Rushton SK (1999) Improving cognitive function after brain injury: the use of exercise and virtual reality. Arch Phys Med Rehabil 80:661-667.

Greengard P, Valtorta F, Czernik AJ, Benfenati F (1993) Synaptic vesicle phosphoproteins and regulation of synaptic function. Science 259:780-785.

Griesbach GS, Hovda DA, Molteni R, Gomez-Pinilla (2002) Alterations in BDNF and synapsin I within the occipital cortex and hippocampus after mild traumatic brain injury in the developing rat: reflections of injury-induced neuroplasticity. Neurotrauma 19:803-814.

Hardingham G, Arnold FJ, Bading H (2001) Nuclear calcium signaling controls CREB-mediated gene expression triggered by synaptic activity. Nat Neurosci 4:261-267.

Heymach JJ, Kruttgen A, Suter U, Shooter EM (1996) The regulated secretion and vectorial targeting of neurotrophins in neuroendocrine and epithelial cells. J Biol Chem 271:25430-25437.

Hilfiker S, Pieribone VA, Czernik AJ, Kao HT, Augustine GJ, Greengard $P$ (1999) Synapsins as regulators of neurotransmitter release. Philos Trans R Soc Lond B Biol Sci 354:269-279.

Hollmann M, Boulter J, Maron C, Heinemann S (1994) Molecular biology of glutamate receptors: Potentiation of $\mathrm{N}$-methyl-D-aspartate receptor splice variants by zinc. Ren Physiol Biochem 17:182183.

Jovanovic JN, Benfenati F, Siow YL, Sihra TS, Sanghera JS, Pelech SL, Greengard P, Czernik AJ (1996) Neurotrophins stimulate phosphorylation of synapsin I by MAP kinase and regulate synapsin l-actin interactions. Proc Natl Acad Sci USA 93:3679-3683.

Jovanovic JN, Czernik AJ, Fienberg AA, Greengard P, Sihra TS (2000) Synapsins as mediators of BDNF-enhanced neurotransmitter release. Nat Neurosci 3:323-329.

Kafitz KW, Rose CR, Thoenen H, Konnerth A (1999) Neurotrophinevoked rapid excitation through TrkB receptors. Nature 401:918921.

Kang H, Welcher AA, Shelton D, Schuman EM (1997) Neurotrophins and time: different roles for TrkB signaling in hippocampal longterm potentiation. Neuron 19:653-664.

Kang HJ, Schuman EM (1995) Neurotrophin-induced modulation of synaptic transmission in the adult hippocampus. J Physiol (Paris) 89:11-22. 
Kawabe K, Yoshihara T, Ichitani Y, Iwasaki T (1998) Intrahippocampal D-cycloserine improves MK-801-induced memory deficits: radialarm maze performance in rats. Brain Res 814:226-230.

Knusel B, Hefti F (1992) K-252 compounds: modulators of neurotrophin signal transduction. J Neurochem 59:1987-1996.

Korte M, Carroll P, Wolf E, Brem G, Thoenen H, Bonhoeffer T (1995) Hippocampal long-term potentiation is impaired in mice lacking brain-derived neurotrophic factor. Proc Natl Acad Sci USA 92: 8856-8860.

Kramer AF, Hahn S, Cohen NJ, Banich MT, McAuley E, Harrison CR, Chason J, Vakil E, Bardell L, Boileau RA, Colombe A (1999) Aging, fitness, and neurocognitive function. Nature 400:418-419.

Laurin D, Verreault R, Lindsay J, MacPherson K, Rockwood K (2001) Physical activity and risk of cognitive impairment and dementia in elderly persons. Arch Neurol 58:498-504.

Levine ES, Crozier RA, Black IB, Plummer MR (1998) Brain-derived neurotrophic factor modulates hippocampal synaptic transmission by increasing N-methyl-D-aspartic acid receptor activity. Proc Natl Acad Sci USA 95:10235-10239.

Lo DC (1995) Neurotrophic factors and synaptic plasticity. Neuron 15:979-981.

Lom B, Cohen-Cory S (1999) Brain-derived neurotrophic factor differentially regulates retinal ganglion cell dendritic and axonal arborization in vivo. J Neurosci 19:9928-9938.

McGlade-McCulloh E, Yamamoto H, Tan SE, Brickey DA, Soderling TR (1993) Phosphorylation and regulation of glutamate receptors by calcium/calmodulin-dependent protein kinase II. Nature 362 : 640-642.

Merlio J, Ernfors P, Jaber M, Persson H (1992) Molecular cloning of rat trkC and distribution of cells expressing messenger RNAs for members of the trk family in the rat central nervous system. Neuroscience 51:513-532.

Messaoudi E, Ying S, Kanhema T, Croll SD, Bramham CR (2002) Brain-derived neurotrophic factor triggers transcription dependent, late phase long-term potentiation in vivo. J Neurosci 22:7453-7461.

Meyer T, Waeber G, Lin J, Beckmann W, Habener JF (1993) The promoter of the gene encoding $3^{\prime}, 5^{\prime}$-cyclic adenosine monophosphate (CAMP) response element binding protein contains cAMP response elements: evidence for positive autoregulation of gene transcription. Endocrinology 132:770-780.

Moller J, Kruttgen A, Heymach JV Jr, Ghori N, Shooter EM (1998) Subcellular localization of epitope-tagged neurotrophins in neuroendocrine cells. J Neurosci Res 51:463-472.

Molteni R, Barnard RJ, Ying Z, Roberts CK, Gomez-Pinilla F (2002a) A high-fat, refined sugar diet reduces hippocampal brain-derived neurotrophic factor, neuronal plasticity, and learning. Neuroscience 112:803-814.

Molteni R, Ying Z, Gomez-Pinilla F (2002b) Differential effects of acute and chronic exercise on plasticity-related genes in the rat hippocampus revealed by microarray. Eur J Neurosci 16:1107-1116.

Murray KD, Hayes VY, Gall CM, Isackson PJ (1998) Attenuation of the seizure-induced expression of BDNF mRNA in adult rat brain by an inhibitor of calcium/calmodulin-dependent protein kinases. Eur J Neurosci 10:377-387.

Nguyen P, Kandel ER (1996) A macromolecular synthesis-dependent late phase of long-term potentiation requiring CAMP in the medial perforant pathway of rat hippocampal slices. J Neurosci 16:31893198.

Patterson SL, Abel T, Deuel TAS, Martin KC, Rose JC, Kandel ER (1996) Recombinant BDNF rescues deficits in basal synaptic transmission and hippocampal LTP in BDNF knockout mice. Neuron 16:1137-1145.

Pieribone V, Shupliakov O, Brodin L, Hilfiker-Rothenfluh S, Czernik AJ, Greengard P (1995) Distinct pools of synaptic vesicles in neurotransmitter release. Nature 375:493-497.
Platenik J, Kuramoto N, Yoneda Y (2000) Molecular mechanisms associated with long-term consolidation of the NMDA signals. Life Sci 67:335-364.

Pozzo-Miller LD, Gottschalk W, Zhang L, McDermott K, Du J, Gopalakrishnan R, Oho C, Sheng ZH, Lu B (1999) Impairments in high-frequency transmission, synaptic vesicle docking, and synaptic protein distribution in the hippocampus of BDNF knockout mice. J Neurosci 19:4972-4983.

Quattrochi JJ, Mamelak AN, Madison RD, Macklis JD, Hobson JA (1989) Mapping neuronal inputs to REM sleep induction sites with carbachol-fluorescent microspheres. Science 245:984-986.

Riddle DR, Lo DC, Katz LC (1995) NT-4-mediated rescue of lateral geniculate neurons from effects of monocular deprivation. Nature 378:189-191.

Riddle DR, Katz LC, Lo DC (1997) Focal delivery of neurotrophins into the central nervous system using fluorescent latex microspheres. Biotechniques 23:928-937.

Rocamora N, Pascual M, Acsady L, de Lecea L, Freund TF, Soriano E (1996) Expression of NGF and NT3 mRNAs in hippocampal interneurons innervated by the GABAergic septohippocampal pathway. J Neurosci 16:3991-4004.

Shen H, Tong L, Balazs R, Cotman CW (2001) Physical activity elicits sustained activation of the cyclic AMP response element-binding protein and mitogen-activated protein kinase in the rat hippocampus. Neuroscience 107:219-229.

Shieh PB, Ghosh A (1999) Molecular mechanisms underlying activitydependent regulation of BDNF expression. J Neurobiol 41:127134.

Song D, Choe B, Bae JH, Park WK, Han IS, Ho W, Earm YE (1998) Brain-derived neurotrophic factor rapidly potentiates synaptic transmission through NMDA, but suppresses it through non-NMDA receptors in rat hippocampal neuron. Brain Res 799:176-179.

Stephens R, Loeb DM, Copeland TD, Pawson T, Greene LA, Kaplan DR (1994) Trk receptors use redundant signal transduction pathways involving SHC and PLC-gamma 1 to mediate NGF responses. Neuron 12:691-705.

Suen P, Wu K, Levine ES, Mount HT, Xu JL, Lin SY, Black IB (1997) Brain-derived neurotrophic factor rapidly enhances phosphorylation of the postsynaptic $\mathrm{N}$-methyl-D-aspartate receptor subunit 1. Proc Natl Acad Sci USA 94:8191-8195.

Tao X, Finkbeiner S, Arnold DB, Shaywitz A, Greenberg ME (1998) $\mathrm{Ca}^{2+}$ influx regulates BDNF expression by a CREB dependent mechanism. Neuron 20:709-726.

Thoenen H (1995) Neurotrophins and neuronal plasticity. Science 270:593-598.

Timmusk T, Belluardo N, Metsis M, Persson H (1993) Widespread and developmentally regulated expression of neurotrophin- 4 mRNA in rat brain and peripheral tissues. Eur J Neurosci 5:605-613.

Tongiorgi E, Righi M, Cattaneo A (1997) Activity-dependent dendritic targeting of BDNF and TrkB mRNAs in hippocampal neurons. J Neurosci 17:9492-9505.

van Praag H, Christie BR, Sejnowski TJ, Gage FH (1999a) Running enhances neurogenesis, learning, and long-term potentiation in mice. Proc Natl Acad Sci USA 96:13427-13434.

van Praag H, Kempermann G, Gage FH (1999b) Running increases cell proliferation and neurogenesis in the adult mouse dentate gyrus. Nat Neurosci 2:266-270.

Walton M, Sirimanne E, Williams C, Gluckman P, Dragunow M (1996) The role of cyclic AMP-responsive element binding protein (CREB) in hypoxic-ischemic brain damage and repair. Brain Res Mol Brain Res 43:21-29.

Watson FL, Heerssen HM, Moheban DB, Lin MZ, Sauvageot CM, Bhattacharyya A, Pomeroy SL, Segal RA (1999) Rapid nuclear responses to target-derived neurotrophins require retrograde transport of ligand-receptor complex. J Neurosci 19:7889-7900.

Wolfman C, Izquierdo LA, Schroeder N, Izquierdo I (1999) Intrahippocampal KN-62 hinders the memory of habituation acquired 
alone, but not simultaneously with a water-finding task. Behav Pharmacol 10:99-104.

Yin JC, Tully T (1996) CREB and the formation of long-term memory. Curr Opin Neurobiol 6:264-268.

Ying S, Futter M, Rosenblum K, Webber MJ, Hunt SP, Bliss TV, Bramham CR (2002) Brain-derived neurotrophic factor induces long-term potentiation in intact adult hippocampus: requirement for
ERK activation coupled to CREB and upregulation of Arc synthesis. J Neurosci 22:1532-1540.

Zhang WN, Basr T, Feldon J (2001) The ventral hippocampus and fear conditioning in rats: different anterograde amnesias of fear after infusion of $\mathrm{N}$-methyl-D-aspartate or its noncompetitive antagonist MK-801 into the ventral hippocampus. Behav Brain Research 126:159-174. 